\title{
The role of source of protein in regulation of food intake, satiety, body weight and body composition
}

\begin{abstract}
Dietary proteins elicit a wide range of metabolic and physiologic functions that are far beyond their traditional role as sources of energy and also indispensable amino acids. Proteins play a significant role in the regulation of appetite, food intake, body weight, and body composition. Their role in regulation of blood pressure, glucose and lipid metabolism, bone metabolism, and immune system is also shown. The role of proteins as the most satiating macronutrient in regulation of food intake, body weight and body composition is well-studied. The direct interaction between dietary proteins and the gastro-intestinal (GI) tract via communication with endogenous satiety signals, in addition to their effects on protein synthesis are major underlying mechanisms. The interaction of proteins with the GI tract can be elucidated by their effect on gastric emptying rate, GI transport and absorption, GI-brain communication via gut-brain axis, and more recently by their effect on gut micro biota. However, there is increasing evidence indicating that these effects are sourcedependent. Physicochemical properties of individual proteins, including digestion kinetics, digestibility, amino acid composition and sequence, bioactive peptides and also non-protein bioactive components conjugated with proteins are potential factors determining their physiologic and metabolic properties. Therefore, the purpose of this review is to examine the most recent findings about the role of the source of protein in regulation of food intake, body weight, and body composition.
\end{abstract}

Keywords: dietary proteins, food intake, appetite, satiety, body weight, body composition

\author{
Volume 6 Issue 6 - 2017
}

\author{
Emily Greco,' Andrew Winquist, ${ }^{2}$ Thomas \\ Jacob Lee, ${ }^{2}$ Shari Collins, ${ }^{2}$ Zach Lebovic, ${ }^{2}$ \\ Tara Zerbe-Kessinger, ${ }^{2}$ Alireza Jahan Mihan ${ }^{2}$ \\ 'Vincent's Medical Center Southside, USA \\ ${ }^{2}$ Department of Nutrition and Dietetics, University of North \\ Florida, USA
}

\begin{abstract}
Correspondence: Alireza Jahan Mihan, Department of Nutritional and Dietetics, Brooks College of Health, University of North Florida, I UNF Dr. BLDG 39, Room 3057A, Jacksonville, Florida, USA, Postal code 32224, Tel (904) 6205359, Fax (904) 6201942, Email alireza.jahan-mihan@unf.edu
\end{abstract}

Received: May 30, 2017 | Published: July 27, 2017
Abbreviations: AA, amino acid; BAP, bioactive peptide; $\mathrm{BBB}$, blood brain barrier; BCAA, branched chain amino acid; BMI, body mass index; CCK, cholecystokinin; $\mathrm{CHO}$, carbohydrate; DPP-IV, dipeptidyl peptidase IV; EWH, egg white hydrolysate; GI, gastro-intestinal tract; GLP-1, glucagon like peptide; GMP, glycomacropeptide; ICV, intracerebroventricular; IPP, isoleucineproline-proline; kg, kilogram; m, meter; PYY, peptide YY; VPP, valine-proline-proline

\section{Introduction}

Obesity and its comorbidities are on the rise globally. Excessive calorie intake along with sedentary life style is major contributing factors in etiology of obesity. Therefore, understanding factors affecting appetite, satiety and also food selection is critically important. The mechanisms associated with food intake regulation originate from a sequence of complex interactions between the gastrointestinal (GI) tract and areas of the brain, particularly the hypothalamus and the brainstem so called "gut-brain axes". ${ }^{1}$ It includes the main neuroendocrine regulatory pathways that control food intake in short- and long-term. ${ }^{2}$ This integrated approach is designed to maintain metabolic homeostasis and also stabilize body weight and body composition in long-term by regulating energy and macro- and micro-nutrients' intake in short- and long-term.

Mechanisms regulating satiety can be categorized as short- and long-term. More than 40 hormones influence short-term food intake by regulating meal initiation, termination, size, and frequency primarily through GI-tract signals including cholecystokinin (CCK), Glucagon like peptide (GLP-1), peptide YY (PYY) and amylin as satiety signals and also ghrelin as a hunger signal2. Moreover, food intake regulatory signals including leptin and insulin influence long-term energy intake in response to current energy stores within the body in the form of fat deposits. Although these signals target different areas of brain, the hypothalamus is the predominant site of regulation. ${ }^{2}$

Proteins suppress food intake more than fat and carbohydrate (calorie/calorie). ${ }^{3}$ However, the underlying mechanisms are varied, complex and unclear. Individual properties of proteins including amino acid composition and sequence, digestion kinetics, digestibility and encrypted bioactive peptides within their amino acid sequences are potential factors influencing their physiologic and metabolic properties ${ }^{4}$ and also determining their effect on food intake, satiety, and body weight in a source-dependent manner.

\section{Food sources of proteins}

There is a variety of proteins from a wide spectrum of food sources such as muscle, milk, egg, plant, pulse, soy, and other oilproducing plants. Fish, poultry, and red meat are major sources of muscle proteins. Based on their solubility they can be divided to 3 groups: 1- Sarcoplasmic such as myoglobin, 2- Myofibrillar such as myosin and actin and finally 3- Stromal proteins such as collagen and elastin. ${ }^{5}$ Milk proteins contribute to up to $3.5 \%$ of cow milk. Casein and whey are the two major proteins in milk. They comprise about $80 \%$ and $20 \%$ of cow's milk protein respectively while this proportion is reversed in human milk. Egg proteinscontribute to $13 \%$ of the whole egg content. Egg proteins include egg white proteins such as albumen and yolk. ${ }^{5}$ Egg white is a good source of high quality protein; however, ovoinhibitor, a serine proteinase inhibitor in egg 
white can inhibit a digestive enzyme (e.g. trypsin and chymotrypsin) which is a factor that can influence the regulatory functions of the GI tract, particularly when raw egg whites are consumed or used without thermal processing. ${ }^{5}$

Plant proteins are varied and can be found in cereal, pulse, and legumes. Protein content varies among plants: from $8 \%$ in cereals and rice to $12 \%$ in wheat. There are two different types of cereal proteins: 1- Proteins that are metabolically active such as cytoplasmic proteins and 2- Storage proteins. The cytoplasmic proteins contain protease inhibitor enzymes, while storage proteins include albumins and the globulins--prolamins, and glutelins. ${ }^{5}$

Pulse proteins are from legumes. Pulses contain anywhere from $17 \%$ to $30 \%$ protein. Globulins such as legumin and vicilin, and albumins such as enzymatic proteins, protease inhibitors, amylase inhibitors and lectins, are major proteins in pulses. Consumption of unprocessed pulse seeds decrease protein digestibility due to the effects of anti-nutritional factors, such as trypsin and chymotrypsin inhibitors.

Soy proteins are from soybeans which are high in protein content (35\% to $40 \%$ of dry weight). Approximately, $90 \%$ of the soybeans proteins are storage proteins, mainly $\beta$-conglycinin (a glycoprotein including three subunits), and glycinin (a hexameric protein).

In oilseed crops, storage proteins are the largest fraction of all proteins contained to, include cruciferin (12S protein) in canola or rapeseed, 11S protein in cottonseed, zein in corn, arachin in peanut, carmin in safflower, $12 \mathrm{~S}$ protein in flax and hemp, $\alpha$-globulin in sesame, and helianthin in sunflower. Oilseed crops contain albumins, globulins and glutelins which have a wide spectrum of biological functions.

\section{Structure-related properties of proteins}

Many properties of proteins including amino acid sequence, digestion kinetics, digestibility and encrypted bioactive peptides within their amino acid sequences are dependent on the structure and physicochemical properties of proteins. These properties are varied among proteins and results in a source-dependent metabolic and physiological response to proteins in pre- and post-absorption phases. Digestion kinetics of proteins are depends on their source and it can be varied due to their difference in physicochemical properties including isoelectric $\mathrm{pH}$ and size. Digestion kinetics is an influencing factor on the effect of proteins on both food intake regulation and protein synthesis.

For example, casein is considered as a 'slow' protein, whereas whey protein is considered a 'fast' protein. It may explain a rapid and strong satiety effect induced by whey protein vs. a moderate and more persistent satiety effect of casein. ${ }^{5}$ Consumption of soy proteins, which has faster digestion kinetics, compared with total milk proteins resulted in faster nitrogen absorption in the GI tract. ${ }^{6}$ Moreover, the digestion rate of fish proteins has been shown to be slower than that of beef and chicken proteins. ${ }^{5}$ Food matrix is also a factor influencing the digestion rate of proteins. The ultimate rate of the digestion process at each meal is determined by food matrix. Fat and fiber reduce GI transit time which when eaten in combination with protein can affect the rate at which proteins are absorbed. Moreover, solid and liquid forms of foods differently affect the absorption rate of free amino acid (AA) in the GI tract. It tends to be slower after ingesting a solid meal compared to a liquid meal. ${ }^{5,7}$ The difference in digestion kinetics not only influences the rate of absorption but also determine their postabsorptive physiologic and metabolic fate of proteins which has been discussed in the following.

Digestibility of proteins can also influence their metabolic functions. By varying biological mechanisms, protein digestibility may affect the sense of fullness and subsequent overall food intake. ${ }^{4}$ Additionally, post prandial AA. Bioavailability may also be influenced by the rate of digestibility. ${ }^{6}$ Processing is also a key factor that can potentially alter the rate of digestibility of proteins. Processing can alter the bioavailability and physicochemical properties of proteins by affecting their solubility, heat liability and isoelectric $\mathrm{pH} .{ }^{8,9}$ Processing methods (e.g., thermal treatment and fermentation) have favorable effects on digestibility of proteins by increasing their digestibility and peptide release. ${ }^{10}$

Animal proteins usually have a higher digestibility rate than plant proteins when they are ingested in their natural form. Moreover, protein digestibility can be reduced by anti-nutritional factors (e.g. trypsin and chymotrypsin inhibitors) encrypted in some plant proteins including dry peas, lentils, beans and chickpeas. Anti-nutritional factors are activated in these sources of proteins when they are unprocessed. ${ }^{5}$ However, beneficial effect of trypsin inhibitors derived from peanuts on food intake and weight control in male Wistar rats. Supplementation with trypsin inhibitor resulted in decreased body weight gain and food intake and increased CCK production. ${ }^{11}$ Similarly, protease inhibitors from potato decreased food intake and body weight in rats by increasing circulating CCK.${ }^{12}$ Raw egg whites that are used without thermal processing for some food applications may also result in inhibition of digestive enzymes such as trypsin and chymotrypsin due to active ovoinhibitor exist in raw egg whites. Inhibition of trypsin and chymotrypsin alters the GI function and eventually will decrease digestibility and bioavailability of proteins. ${ }^{13}$

There is also growing evidence supporting the role of bioactive peptides (BAPs) in various physiological functions that were originally attributed to proteins. BAPs derived from milk and marine sources have shown anti-obesity properties. ${ }^{14-16}$ BAPs are encrypted in amino acid sequences of proteins and are activated upon digestion through the process of hydrolysis. Many BAPs can be detected in milk proteins (casein and whey protein), soy protein, and other types of proteins. Activation of BAPs can be through either digestion process in the GI tract or through the manufacturing process (hydrolysis, fermentation, etc). For example, BAPs in whey proteins are generated in vivo, during their digestion in the GI tract, and in vitro, by the action of milk proteases, enzymes from starter cultures, or even after resultant actions of microbial and digestive proteases. ${ }^{17}$ Almost all known whey-derived bioactive peptides can be generated by digestive proteases. Bioactive peptides exert their effects by binding to specific receptors in the intestinal lumen or in target organs and tissues after absorption into the bloodstream. There is growing body of evidence to suggest interactions between food borne peptides and endocrine gut peptides such as CCK-1, Glucagon-like Peptide-1 (GLP-1) and Peptide YY (PYY) in the GI tract that support their role in the regulation of food intake. However, these actions are not solely attributed to proteins and their peptides, but rather to a synergism between proteins and other components such as certain vitamins and minerals within a meal. ${ }^{18}$ Anti-microbial properties of BAPs are also shown. ${ }^{19}$ They can protect the host from the invasion of bacteria by disrupting the microbial membrane. ${ }^{19,20}$ 
Lactoferrin, a BAP derived from whey protein and its sub-fragment lactoferricin exhibited antibacterial properties against a wide range of gram negative and positive bacteria, fungi (e.g., Candida) and protozoa (e.g., Toxoplasma gondii). ${ }^{21,22}$ The effect BAPs on composition of microbiota has also been studied: Egg white hydrolysate (EWH) when was given as supplement to rats resulted in changes the composition of microbiota. ${ }^{23}$

Authors suggested that the anti-obesity properties of EWH can be attributed to its lowering effect on short-chain fatty acid production of microbiota plus changes in the composition of microbiota tended to be more similar to the composition of microbiota observed in lean rats. It is still unclear if the effect of BAPs on food intake and satiety is limited to the pre-absorptive stage or they can survive the hydrolysis process I the GI tract and absorb intact and remain physiologically active in post-absorptive stage. Several studies reported that gammaglobulins and other milk proteins can be absorbed intact in mammalian intestine ${ }^{24}$ while some other studies suggested limited bioavailability of BAPs in post-absorptive stage. ${ }^{25}$ BAPs such as Valine-ProlineProline (VPP) and Isoleucine-Proline-Proline (IPP) have been found intact in the plasma in human. ${ }^{26}$

\section{Regulation of food intake, satiety and protein synthesis}

The fact that proteins affect food intake and satiety in a sourcedependent manner has been researched extensively in both animals and humans. Several mechanisms have been suggested to explain the satiety effect induced by proteins: "The Amino Acid Theory" suggests that the satiety effect of proteins is due to increased plasma amino acid level following protein ingestion. ${ }^{27}$ However, the fact that rapid satiety induced by proteins during and right after meal cannot be simply explained by their effect on plasma amino acid concentration since it occurs later after meal. Therefore, increases in plasma amino acids concentration in post-absorption phase combined with their stimulating effect on secretion of satiety signals including CCK and GLP-1 can be potential mechanisms for satiety response to proteins. ${ }^{28}$

Food intake suppression induced by proteins depends on the source and time suggesting that each protein gives rise to unique digestive products (e.g. bioactive peptides). This effect is dependent on the source (whey $>$ albumin $>$ soy $>$ casein). Similarly, although source of protein is an important regulator of food intake in humans, it is also a regulator of the timing between meals. ${ }^{29}$ In a comparison of the effect of $45 \mathrm{~g}$ preloads of whey, soy protein, and sucrose and egg albumin on food intake, one hour later, of young men, whey protein suppressed food intake the most, followed by soy. In contrast, egg albumin had no effect on food intake. In another study, whey and casein preloads given to young men decreased their food intake similarly at $90 \mathrm{~min}$, but at $150 \mathrm{~min}$, casein suppressed food intake more than whey protein. Whey protein which is classified as a fast protein suppressed food intake more than casein in a short period of time while the satiety effect of casein was persistent during a longer period of time. ${ }^{30}$ Moreover, the effect of whey protein on food intake can be partially attributed to glycomacropeptide (GMP), a sub-fragment of $\kappa$-caseins that comes along with whey protein during the cheese making process. This effect is evidenced by the stronger satiety effect of complete whey protein (including GMP) when compared with the effect of whey protein with no GMP fraction., ${ }^{5,731}$ In another study, whey protein (with negligible amount of GMP) and mildly glycosylated GMP have shown similar satiety effect at first hour of food intake in Wistar rats.
Authors suggested that GMP content of whey protein contribute to the satiety effect of whey protein proportionally since GMP and whey protein showed similar effect on satiety. ${ }^{32}$

Although protein-rich plant foods have recently been advertised as being equivalent to animal products, only a few studies compared the effect of animal and plant proteins, with the exception of soy protein, on appetite, satiety, and subsequent food intake. In a randomized, doubleblind, crossover design study, subjects were given equal amounts of either soy or beef protein at lunch. ${ }^{33}$ No difference in plasma PYY or GLP-1 after consumption of beef versus soy was observed. Authors suggested that there is no difference in satiety induced by soy protein and beef protein. In another study, soy protein exhibited stronger short-term satiety in comparison with egg albumin. ${ }^{17}$ However, when pork was compared with soy, the pork was more satiating. ${ }^{1,31}$ The satiety effect of Pea protein has also been studied. Pea protein showed an equivalent or even slightly more satiating effect compared to whey. ${ }^{34,35}$ In another study the interactive effect of pea protein and fiber on food intake was examined. Men $(n=15)$ randomly consumed one of the following treatments: 1- pea hull fiber, 2- pea protein, 3pea protein plus hull fiber, 4- yellow peas. Food intake was measured at a pizza meal and after for $135 \mathrm{~min}$. No difference in food intake or appetite was observed. ${ }^{36}$ When compared to other meat sources (beef and chicken), fish protein showed a greater satiety effect in both short (baseline to 90 ) and longer (2-4hrs) period of time..$^{37,38}$

The effect of casein, the main protein constituent of bovine milk, on food intake and satiety has also been extensively studied in both humans and animals. Overall, casein has been shown to have a slower digestion and absorption compared to whey or soy protein. ${ }^{30,39}$ Higher concentrations of casein or soy protein ( 25 en\% versus 10 en $\%)$ induced higher satiating effects, which can be attributed to their amino acid profile kinetics. ${ }^{39}$ Compared with casein, pea protein hydrolysate, and soy protein, whey protein resulted in a higher blood concentrations of postprandial amino acids and satiety hormones at a more rapid pace. ${ }^{40,41}$ However, in a single blind, randomized, crossover controlled trial, 32 participants received $20 \mathrm{~g}$ of whey, egg protein, casein and pea protein in a random order. Food intake was lower after 30minutes after casein compared to whey and egg proteins. ${ }^{35}$ However, in another study, no difference in effects between whey and casein was observed. ${ }^{42}$ This discrepancy can be due to the difference in the dose and also the timing. The dose-response effect of proteins on satiety is shown. In a randomized, single blind, controlled trial, 25 subjects received meals with $25 \%$ and $10 \%$ of kcal from casein. The meal containing $25 \%$ casein had greater satiating effects compared to a meal with $10 \%$ casein. ${ }^{43}$ In another study, casein had the longest satiety effect followed by soy and then whey after five and one halfhours post-test meal. ${ }^{41}$ Casein also showed lower energy intake when compared to whey protein. ${ }^{44}$ These results suggest that both source and the dose are determining factors on the effect of proteins on satiety and food and energy intake.

The post-absorptive metabolic and physiologic fate of proteins is determined by synergistic effect of various characteristics of proteins including digestibility, bioavailability, digestion kinetics, amino acid composition and also bioactive peptides encrypted in their amino acid composition. Individual dietary proteins elucidate various catabolic and anabolic activities systematically, particularly in the liver and brain. Amino acid concentrations affect neural activity in a sourcedependent manner which may be attributed to the difference in their digestion and absorption kinetics. ${ }^{5}$ The difference in digestion 
kinetic of casein and whey as they classified as slow and fast proteins respectively, also influence postprandial circulating plasma amino acid concentrations. In congruence with the gastric emptying rates seen, whey protein has been shown to result in an increased rise rate and peak of plasma amino acid levels following ingestion. ${ }^{5}$ Ingestion of whey protein results in larger post-meal aminoacidemia compared with casein resulted in a higher protein synthesis. On the other hand, casein reduces protein breakdown in larger extent compared with whey protein. ${ }^{45}$

In young, healthy male subjects, the rapid absorption and composition of whey protein results in greater levels of wholebody protein synthesis. ${ }^{6}$ Several mechanisms have been proposed to explain the favorable effect of whey protein on protein synthesis: Whey protein is classified as fast protein due to its rapid digestion and absorption resulting in a strong pick in amino acids concentration that stimulates protein synthesis. Moreover, whey protein is reach in branched chain amino acids (BCAAs). The stimulating effect of BCAAs particularly leucine is well-documented. However, it is also reported that whey protein containing higher levels of indispensable amino acids compared to casein that may lead to higher deamination and increased breakdown. ${ }^{6}$ The differences in amino acid kinetics have also been reported in studies comparing milk proteins (primarily casein) to that of soy protein, a rapidly digested protein. ${ }^{46}$ The level of protein synthesis after ingestion of proteins also depends on the match between the composition of indispensible amino acids in ingested protein and the amount that is required for protein synthesis. ${ }^{39}$ It may explain why soy protein which is a fast protein like whey protein resulted in lower protein synthesis compared with animal proteins. ${ }^{39}$

Although the digestion kinetics determines the rate of plasma amino acid concentrations, variations in amino acid composition is an independent variable influencing food intake and appetite, whereby indicating the significance of the role of individual amino acids. In fact, some amino acids act as precursor for neurotransmitters involved in the regulation of food intake and appetite, such as tryptophan as precursor of serotonin. ${ }^{47,48}$ Brain serotonin levels are inversely associated with food intake and body weight. ${ }^{49}$ Ingestion of BCAAs decreases uptake of brain tryptophan and eventually lowers serotonin synthesis and release by competing with tryptophan transportation into the brain. ${ }^{50}$ Therefore, the BCAA/aromatic amino acids ratio is particularly important. Intra cerebro ventricular (ICV) or oral administration of leucine reduces food intake and body weight in rats and mice. ${ }^{51,52}$ However, the results are controversial. Some studies indicated that the increased availability of leucine in hypothalamus is a strong signal that reduces food intake in rats, while other studies showed that an increased $\mathrm{BCAA} /$ aromatic amino acid ratio resulted in increased appetite and protein synthesis. ${ }^{53}$ Tyrosine is another amino acid that acts as precursor for dopamine and norepinephrine, two hormones that are involved in regulation of appetite and food intake. ${ }^{54}$ The direct role of tyrosine on food intake regulation is yet to be determined. However, some studies have shown altered tyrosine concentrations in associated with anorexia. ${ }^{55}$

After consumption of a casein meal compared with a soy protein meal in humans, plasma concentrations of serine, tyrosine, valine, isoleucine, branched chain amino acids (BCAAs), lysine and total amino acids are higher; arginine and tryptophan are lower which is consistent with the composition within the food source. Moreover, a larger portion of amino acids are degraded to urea, resulting in less protein synthesis after consumption of soy protein due to an increased absorption rate of soy protein when compared with casein. In addition, hormonal responses to casein and whey were considerably different: Higher concentration of plasma insulin have been observed at $60 \mathrm{~min}$ after whey protein consumption compared with casein ingestion. Distinct differences in gastric emptying rates, subsequent rise in circulating plasma amino acid levels and rates of protein synthesis have also been seen in the dairy proteins, casein and whey. ${ }^{5}$ In a study by Anderson et al., ${ }^{22}$ healthy males showed that the short-term (up to 2 hours) following a meal preload of whey protein reduced food intake greater than soy or egg albumin. ${ }^{48}$ In another study whey and casein preloads given to young men decreased their food intake similarly at $90 \mathrm{~min}$, but at $150 \mathrm{~min}$, casein suppressed food intake more than whey. Acheson et al., ${ }^{41}$ demonstrated that in the 5 and a halfhours following consumption of casein, whey, and soy proteins, casein resulted in increased levels of fullness and lowest energy consumption throughout the study period. ${ }^{56}$

The satiety effect of BAPs is also studied. Alphalactalbumin, a whey-derived peptide contains an abundant amount of tryptophan that, when ingested, increases plasma tryptophan concentration. ${ }^{57,58}$ Although alphalactalbumin has been shown to suppress hunger more than gelatin (low tryptophan content), no difference in perceived hunger was noted between alphalactalbumin and alphalactalbumin added to gelatin. Authors suggested that tryptophan had no predominant effect on the role serotonin on appetite. ${ }^{59}$ The satiety effect of BAPs released form soy protein has also been investigated. $\beta$-conglycinin, a peptide derived from soy protein, stimulates CCK release, ${ }^{60}$ and delays gastric emptying and suppresses food intake. ${ }^{54,61}$ Food derived peptides alter metabolic responses to gut hormones; therefore, suggesting that the satiety effect of hydrolysate form of proteins is stronger than the effect of intact protein, but again it depends on the source. Thus, protein through BAPs unique to the protein source and dependent on its tertiary structure and amino acid composition, not only initiates satiety, but also contributes to post-absorptive processing of glucose and amino acids. Moreover, it is suggested that in the various proteins studied, each has its own unique bioactive peptides leading to differing digestion kinetics. ${ }^{62}$

It is an increasing recognition that the gastrointestinal tract contains a plethora of peptide hormones that contribute to food intake regulation..$^{30} \mathrm{CCK}$ as one of the first hormones that has been discovered received considerable study. More recently, GLP-1, PYY, amylin and ghrelin have also been targeted in the development of antiobesity agents. ${ }^{28}$ Support for this statement involves the observation that suppression of food intake after protein ingestion involves an interaction between peptides arising from digestion and the activation of receptor sites from satiety hormones in the small intestine. Peptides arising from the digestion of casein and soy suppress food intake partly through CCK-1 and opioid receptors, respectively, that are present in the gut. ${ }^{28}$

In rats, protein preloads suppress food intake and this effect is source and time dependent and throughout various mechanisms. Pupovac and Anderson found that after receiving casein and soy protein as preload, opioid and CCK-1 receptor blockers (Naloxone methiodide and devazepide respectively) diminished their suppression effect on food intake indicating their mediatory role in satiety induced by casein and soy protein in rats. Naloxone methiodide (peripheral opioid receptor blocker) increased food intake after casein preload but not after soy preload while devazepide increased food intake after both casein and soy protein preloads. The increased activation of 
satiety signals following casein was consistent with other findings in which ingestion of casein leads to increased levels of satiety compared to soy. ${ }^{29}$ In humans, plasma concentration of CCK and GLP-1 were increased significantly after administration of casein and whey, the major milk proteins. ${ }^{28}$ Based on "Amino acid theory", satiety effect of proteins is due to increased plasma amino acid level after protein ingestion. This concept is supported by Hall et al. Post-absorptive elevation of plasma amino acids consistent with an increase in concentration of both CCK and GLP-1 as potential mediators of the satiety induced by whey protein is observed. ${ }^{28}$ These findings are consistent with three randomized, double-blinded crossover studies conducted by Bowen et al., ${ }^{63}$ considering the impact of protein source on the appetite response to a mixed meal is particularly important. This conclusion is supported by several other studies that subjectively measured food intake over a period ofdays. However, amino acid changes in fluid bathing the neurons in a number of brain regions occurs too late to explain short-term feeding responses to protein ingestion. Therefore, it is more likely that signals from the GI tract are the first wave of satiety signals.

The effect of taste receptors on food intake regulation have been found throughout the oral cavity and GI tract. For example, T1R and $\mathrm{T} 2 \mathrm{R}$ are taste receptors that are expressed in oral cavity and also in GI mucosa. They are distributed in various regions of the GI tract from the oral cavity to the lowest part of the colon. Moreover, gut hormone receptors, including CCK and vasoactive intestinal peptide (VIP), are also expressed in taste buds of the oral cavity. The vagus nerve mediates common nutrient sensing from the oral cavity and the GI tract. The vagus nerve is the primary neuroanatomical circuit in the gut-brain axis transmitting meal-related signals from the GI mucosa to the central nervous system and is instrumental in regulation of ingestive behavior, nutrient absorption, GI secretion, and stomach emptying as well as conscious sensations (e.g., satiety, nausea, and discomfort). ${ }^{5}$ Transfer of signals to the brain and back to the liver was shown to be by vagal mechanisms in animals following high fat feeding. Moreover, the stimulating effect of amino acids particularly glutamate on vagus nerve has been shown. ${ }^{64}$ Because dietary protein is a stronger stimulant of CCK release and also releases peptides that activate CCK vagal receptors, this may explain the reduction in post-meal glycemia observed after whey protein ingestion. ${ }^{6}$ This effect of whey protein, unlike glucose, occurs in part by insulinindependent mechanisms. ${ }^{8}$ Pre-meal consumption of whey protein increased plasma concentrations of GLP-1 and PYY. These hormones inhibit gut motility and decrease time of gastric emptying to rapidly cross the blood-brain barrier (BBB) to directly transmit signals that inhibit gastric emptying. Their increased blood concentration may be explained by both increased synthesis in enteroendocrine L-cells, but also by an inhibitory action of whey protein on dipeptidyl peptidase IV (DPP-IV) which rapidly breaks down circulating peptide. ${ }^{17}$

There is increasing evidence indicating that the source of protein in maternal diet may also influence the development of food intake regulatory systems in offspring. In one study, offspring born to rat dams fed a soy protein diet had higher food intake compared with those born to dams fed a casein-based diet during pregnancy and lactation. Moreover, offspring born to dams fed soy protein-based diet had higher body weight, and also developed some characteristics of metabolic syndrome including higher blood pressure and glucose intolerance, suggesting that in utero programming of regulatory systems had occurred by proteins in a source-dependent manner. The mediating role of CCK-1, but not peripheral opioid receptors, in satiety effect of proteins in offspring was also influenced by source of protein in maternal diet. ${ }^{4}$
It is evident that the effect of proteins on food intake is dosedependent. ${ }^{65}$ The interactive effects of protein content and protein source of the diet have also been examined. In a single-blind study, soy, casein and whey based custards were compared to determine the differences in short term food intake regulation. The subjects were 30 healthy males and females ages 18-40 with a BMI of 22-30. Subject received a standard breakfast with casein-, soy, or whey-protein with either 10/55/35 (normal) or 25/55/20 high protein/carbohydrate/fat in a randomized, single-blind design. Lunch was given 180 min later ad libitum. Whey had stronger satiating effect compared with soy or casein. When protein content of the diet was $10 \%$ of total calorie, whey decreased hunger more than casein or soy. When protein content was $25 \%$ of total calorie, there were no differences in appetite ratings. The results of this study suggests that quickly digested proteins have more satiety effect than slowly digesting proteins in lower concentration $(10 \%)$ but there is no significant difference between satiety effects of proteins when given in a greater dose $(25 \%) .{ }^{66}$

The role of structure-related properties of proteins in their effect on appetite and food intake has also been investigated by few studies. However, the results are inconsistent. In one study, adult normal weight women $(n=20)$ received either intact whey protein or free amino acid mixture simulating the amino acid composition of whey protein $(52 \mathrm{~g})$ as part of isoenergetic preload meals (approximately $1800 \mathrm{cal}$ ). No significant difference in appetite, food intake at $120 \mathrm{~min}$ was observed. Authors suggested that the satiating effect of whey protein may be related to its specific amino acid composition ${ }^{67}$ However, the timing of the measurement (120min) might be too late since whey protein is a fast protein and in many studies, its effect was more significant within 1 hour after administration. In another study, the effect of intact whey protein and amino acid-based diets fed during pregnancy and lactation on body weight, food intake and intake regulatory hormones in both mothers and their offspring of Wistar rats was tested. Amino acid-based diet resulted in lower body weight and food intake in both mothers and offspring. However, systolic blood pressure and fasting blood glucose were significantly higher in offspring born to mothers fed an amino acid-based diet compared with those born to mothers fed an intact protein diet. ${ }^{68}$

\section{Regulation of body weight and body composition}

The effect of both protein content and protein source of the diet on regulation of body weight and body composition is well-studied. ${ }^{69-72}$ High protein diets have been a key component of majority of weight loss programs. They suppress food intake and consequently reduce the calorie intake while support lean body mass by stimulating the protein synthesis. Proteins affect body weight and body composition throughout various mechanisms including their thermogenic effect, their effects on food intake and also their effect on protein synthesis.

In the obese animal model, high protein diets resulted in decreased food intake and greater weight loss. While high protein diets are known to be effective at supporting weight loss, the effect of protein source is still unclear. In one study, rats were given a high fat diet for 8 weeks to become obese. Thereafter, they were randomized into either a whey-based or red meat-based diet group for 6weeks. At the end of the study, whey protein reduced food intake and insulin levels compared with rats fed a red meat-based diet. ${ }^{73}$ In another study, corn gluten hydrolysate reduced body weight after 8 weeks of administration in high-fat diet-induced obese (DIO) rats compared with casein, wheat gluten and soy protein fed rats. Moreover, epididymal fat pad and plasma triglycerides were the lowest among 
protein fed rats and were significantly lower than control group. ${ }^{74}$ In another study, obese rats who received corn gluten hydrolysate-based diet for 8 weeks had lower food intake, body weight gain, and food efficiency ratio compared with those who received casein-, branchedchain amino acids- and leucine-based diets. Moreover, insulin levels and c-peptide levels were lower and lean body mass was higher in rats fed the corn gluten hydrolysate-based diet compared to the other groups. ${ }^{75}$ The effect of beef and chicken consumption on body weight in overweight women was also compared. Overweight and obese women $(\mathrm{n}=61)$ ages $35-51$ with BMI $32.1 \pm 3.4 \mathrm{~kg} / \mathrm{m}^{2}$ given a low calorie diet (calculated-deficit diet: $-500 \mathrm{cal}$ ), relative to their unique caloric needs, and randomized to either the chicken or beef group. No significant difference in weight loss between the two groups was observed but a significant reduction in body weight and fat percentage occurred in both groups. ${ }^{76}$ Moreover, the effect of whey protein, soy and casein on body weight was compared in two following studies. ${ }^{77}$ In both studies the participants were overweight or obese and the addition of the protein source was in the form of a supplement to be taken around breakfast and dinner times. In the first study, 90 overweight and obese participants randomly assigned to 3 groups and received either whey, soy protein or isoenergetic amount of $\mathrm{CHO}$ as supplement twice a day for 23 weeks. No difference between two groups was observed. However, body weight, fat mass and waist circumference were significantly lower in the whey supplemented group compared with control. In the second study, the effect of whey and casein on plasma lipid profile and also insulin was compared. Participants $(\mathrm{n}=70)$ with age of $48.4 \pm 0.86$ years and BMI of $31.3 \pm 0.8 \mathrm{~kg} / \mathrm{m}^{2}$ assigned to 3 groups and received either whey casein or isocaloric $\mathrm{CHO}$ as supplement. Triglycerides, lipoproteins and insulin levels were significantly lower in the whey protein group as compared to the casein and control groups. This study was done in free living adults who were told to only change their diet to accommodate the excess calories the supplement was providing.

\section{Summary}

Proteins possess the strongest satiety effect among the macronutrients. This effect is both dose and source-dependent. Various characteristics of proteins including digestibility, digestion kinetics, amino acid composition and sequence, bioactive peptides encrypted within the protein structures and also non-protein bioactive components conjugated with proteins are potential factors that determine physiologic and metabolic role of individual proteins. These characteristics also play a key role in the effect of proteins on satiety, food intake and body weight and body composition. However, underlying mechanisms are complex and still unclear. This complexity comes from various factors including factors related to the physicochemical characteristics of individual proteins, processing methods and also food matrix.

\section{Conclusion}

Current literature supports the notion that the effect of proteins on food intake and appetite is source-dependent. This may highlight the possible role of the characteristics of proteins including amino acid composition and structure-related characteristics such as digestibility, digestion kinetics, BAPs and also non-protein bioactive components conjugated with proteins that are unique for each protein.

\section{Acknowledgements}

None.

\section{Conflict of interest}

Author declares that there is no conflict of interest.

\section{References}

1. Paddon-Jones D, Westman E, Mattes RD, et al. Protein, weight management and satiety. Am J Clin Nutr. 2008;87(5):1558S-1561S.

2. Konturek SJ, Pepera J, Zabielski K, et al. Brain gut axis in pancreatic secretion and appetite control. J Physiol Pharmacol. 2003;54(3):293-317.

3. Long SJ, Jeffcoat AR, Millward DJ. Effect of habitual dietary-protein intake on appetite and satiety. Appetite. 2000;35(1):79-88.

4. Veldhorst M, Smeets AJPG, Soenen S, et al. Protein-induced satiety:effects and mechanisms of different proteins. Physiol Behav. 2008;94(2):300-307.

5. Jahan-Mihan A, Luhovyy BL, Khoury DE, et al. Dietary Proteins as Determinants of Metabolic and Physiologic Functions of the Gastrointestinal Tract. Nutrients. 2011;3(5):574-603.

6. Gilbert JA, Bendsen NT, Tremblay A, et al. Effect of proteins from different sources on body composition. Nutr Metab Cardiovasc Dis. 2011;Suppl 2:B16-31

7. Veldhorst MA, Nieuwenhuizen AG, Hochstenbach-Waelen A, et al. Dose-dependent satiating effect of whey relative to casein or soy. Physiol Behav. 2009;96(4-5):675-682.

8. Chobert JM. Milk protein modification to improve functional and biological properties. Adv Food Nutr Res. 2003;47:1-71.

9. Shukla TP. Food Protein Deterioration. In Chemical Modification of Food Proteins. Milwaukee, WI: Krause Milling Company; 1982.

10. Hernandez-Ledesma B, Del Mar Contreras M, Recio I. Antihypertensive peptides:Production, bioavailability and incorporation into foods. $A d v$ Colloid Interface Sci. 2011;165(1):23-35.

11. Serquiz AC, Machado RJ, Serquiz RP, et al. Supplementation with a new trypsin inhibitor from peanut is associated with reduced fasting glucose, weight control, and increased plasma CCK secretion in an animal model. J Enzyme Inhib Med Chem. 2016;31(6):1261-1269.

12. Komarnytsky S, Cook A, Raskin I. Potato protease inhibitors inhibit food intake and increase circulating cholecystokinin levels by a trypsin-dependent mechanism. Int J Obes (Lond). 2011;35(2):236-243.

13. Boye J, Zare F, Pletch A. Pulse proteins: Processing, characterization, functional properties and applications in food and fee. Food Res Int 2010;43:414-431.

14. C Torres-Fuentes, H Schellekens, TG Dinan, et al. A natural solution for obesity:bioactives for the prevention and treatment of weight gain A review Nutr Neurosci. 2015;18(2):49-65.

15. Bouglé D, Bouhallab S. Dietary bioactive peptides:Human studies. Crit Rev Food Sci Nutr. 2017;57(2):335-343.

16. Manikkam V, Vasiljevic T1, Donkor ON, et al. A Review of Potential Marine-derived Hypotensive and Anti-obesity Peptides. Crit Rev Food Sci Nutr. 2016;56(1):92-112.

17. Luhovyy BL, Akhavan T, Anderson GH. Whey proteins in the regulation of food intake and satiety. J Am Coll Nutr. 2007;26(6):704S-712S.

18. Meneguetti BT, Machado LD, Oshiro KG, et al. Antimicrobial Peptides from Fruits and Their Potential Use as Biotechnological Tools-A Review and Outlook. Front Microbiol. 2017;7:2136. 
19. Kang SJ, Kim DH, Mishig-Ochir T, et al. Antimicrobial peptides:their physicochemical properties and therapeutic application. Arch Pharm Res. 2013;35(3):409-413.

20. Orsi N. The antimicrobial activity of lactoferrin:Current status and perspectives. Biometals. 2004;17(3):189-196.

21. Tomita M, Wakabayashi H, Yamauchi K, et al. Bovine lactoferrin and lactoferricin derived from milk:Production and applications. Biochem Cell Biol. 2002;80(1):109-112.

22. Meisel H. Multifunctional peptides encrypted in milk proteins. Biofactors. 2004;21(1-4):55-61.

23. Requena T, Miguel M, Garcés-Rimón M, et al. Pepsin egg white hydrolysate modulates gut microbiota in Zucker obese rats. Food Funct. 2017;8(1):437-443.

24. Rao RK. Biologically active peptides in the gastrointestinal lumen. Life Sci. 1991;48(18):1685-1704.

25. van der Pijl PC, Kies AK, Ten Have GA, et al. Pharmacokinetics of proline-rich tripeptides in the pig. Peptides. 2008;29(12):2196-2202.

26. Foltz M, Meynen EE, Bianco V, et al. Angiotensin converting enzyme inhibitory peptides from a lactotripeptide-enriched milk beverage are absorbed intact into the circulation. J Nutr. 2007;137(4):953-958.

27. Mellinkoff SM, Frankland M, Boyle D, et al. Relationship between serum amino acid concentration and fluctuations in appetite. $J$ Appl Physiol. 1956;8(5):535-389.

28. Hall W, Millward D, Long S, et al. Casein and whey exert different effects on plasma amino acid profiles, gastrointestinal hormone secretion and appetite. Br J Nutr. 2003;89(2):239-248.

29. Pupovac J, Anderson GH. Dietary peptides induce satiety via cholecystokinin-A and peripheral opioid receptors in rats. J Nutr. 2002;132(9):2775-2780.

30. Anderson GH, Tecimer SN, Shah D, et al. Protein source, quantity, and time of consumption determine the effect of proteins on short-term food intake in young men. $J$ Nutr. 2004;134(11):3011-3015.

31. Veldhorst M, Nieuwenhuizen A, Westerterp-Plantenga M, et al. Effects of complete whey-protein breakfasts versus whey without GMPbreakfasts on energy intake and satiety. Appetite. 2009;52(2):388-395.

32. Jahan-Mihan A, Labyak C, Arikawa A, et al. The Effect of Devazepide (CCK-1 Receptor Blocker) on Food Intake Suppression Induced by Whey Protein and Glycomacropeptide in Wistar Rats. Current Nutrition \& Food Science. 2017;13(3):198-203.

33. Douglas S, Lasley T, Leidy H. Consuming Beef vs. Soy Protein Has Little Effect on Appetite, Satiety, and Food Intake in Healthy Adults. $J$ Nutr. 2015;145(5):1010-1016.

34. Diepvens K, Häberer D, Westerterp-Plantenga M. Different proteins and biopeptides differently affect satiety and anorexigenic/orexigenic hormones in healthy humans. Int J Obes (Lond). 2008;32(3):510-518.

35. Abou-Samra R, Keersmaekers L, Brienza D, et al. Effect of differen protein sources on satiation and short-term satiety when consumed as a starter. Nutr J. 2011;10:139.

36. Mollard RC, Luhovyy BL, Smith C, et al. Acute effects of pea protein and hull fibre alone and combined on blood glucose, appetite, and food intake in healthy young men-a randomized crossover trial. Appl Physiol Nutr Metab. 2014;39(12):1360-1365.

37. Uhe A, Collier G, O'Dea K. A comparison of the effects of beef, chicken and fish protein on satiety and amino acid profiles in lean male subjects. J Nutr. 1992;122(3):467-472.
38. Borzoei S, Neovius M, Barkeling B, et al. A comparison of effects of fish and beef protein on satiety in normal weight men. Eur J Clin Nutr. 2006;60(7):897-902.

39. Westerterp-Plantenga M, Nieuwenhuizen A, Tomé D, et al. Dietary protein, weight loss, and weight maintenance. Annu Rev Nutr. 2009;29:21-41.

40. Chung Chun Lam S, Moughan P, Awati A, et al. The influence of whey protein and glycomacropeptide on satiety in adult humans. Physiol Behav. 2009;96(1):162-168

41. Acheson K, Blondel-Lubrano A, Bovetto L, et al. Protein choices targeting thermogenesis and metabolism. Am $J$ Clin Nutr. 2011;93(3):525-534.

42. Marsset-Baglieri A, Fromentin G, Gaudichon C, et al. Milk protein fractions moderately extend the duration of satiety compared with carbohydrates independently of their digestive kinetics in overweight subjects. Br J Nutr. 2014;112(4):557-564.

43. Veldhorst MA, Nieuwenhuizen AG, Hochstenbach-Waelen A, et al. Comparison of the effects of a high-and normal-casein breakfast on satiety, 'satiety'hormones, plasma amino acids and subsequent energy intake. Br J Nutr. 2009;101(2):295-303.

44. Alfenas R, Bressan J, de Paiva A. Effect of protein quality on appetite and energy metabolism in normal weight subjects. Arq Bras Endocrinol Metabol. 2010;54(1):45-51.

45. Boirie $\mathrm{Y}$, Dangin M, Gachon $\mathrm{P}$, et al. Slow and fast dietary proteins differently modulate postprandial protein accretion. Proc Natl Acad Sci US A. 1997;94(26):14930-14935.

46. Bos C, Metges CC, Gaudichon C, et al. Postprandial kinetics of dietary amino acids are the main determinant of their metabolism after soy or milk protein ingestion in humans. J Nutr. 2003;133(5):1308-1315.

47. Wurtman RJ, Wurtman JJ. Do carbohydrates affect food intake via neurotransmitter activity? Appetite. 1988;11(Suppl 1):42-47.

48. Leibowitz SF, Alexander JT. Hypothalamic serotonin in control of eating behavior, meal size, and body weight. Biol Psychiatry. 1988;44(9):851-864.

49. Choi S, Disilvio B, Fernstrom MH, et al. Oral branched-chain amino acid supplements that reduce brain serotonin during exercise in rats also lower brain catecholamines. Amino Acids. 2013;45(5):1133-1142.

50. Laviano A, Meguid MM, Inui A, et al. Role of Leucine in Regulating Food Intake. Science. 2006;313(5791):1236-1238.

51. Cota D, Proulx K, Smith KA, et al. Hypothalamic mTOR signaling regulates food intake. Science. 2006;312:927-930.

52. Zhang Y, Guo K, Le Blanc RE, et al. Increasing dietary leucine intake reduces diet-induced obesity and improves glucose and cholesterol metabolism in mice via multimechanisms. Diabetes. 2007;56(6):1647-1654.

53. Sharara AI, Bouras EP, Misukonis MA, et al. Evidence for indirect dietary regulation of cholecystokinin release in rats. Am J Physiol. 1993;265(1 Pt 1):G107-G112.

54. Wellman PJ. Modulation of eating by central catecholamine systems. Curr Drug Targets. 2005;6(2):191-199.

55. D'Andrea G, Ostuzzi R, Bolner A, et al. Study of tyrosine metabolism in eating disorders. Possible correlation with migraine. Neurol Sci. 2008;29(Suppl 1):S88-92.

56. Anderson GH, Moore SE. Dietary proteins in the regulation of food intake and body weight in humans. J Nutr. 2004;134(4):974S-979S. 
57. Markus CR, Olivier B, de Haan EHF. Whey protein rich in alphalactalbumin increases the ratio of plasma tryptophan to the sum of the other large neutral amino acids and improves cognitive performance in stress-vulnerable subjects. Am J Clin Nutr. 2002;75(6):1051-1056.

58. Markus CR, Olivier B, Panhuysen GE, et al. The bovine protein alphalactalbumin increases the plasma ratio of tryptophan to the other large neutral amino acids, and in vulnerable subjects raises brain serotonin activity, reduces cortisol concentration, and improves mood under stress. Am J Clin Nutr. 2000;71(6):1536-1544.

59. Nieuwenhuizen AG, Hochstenbach-Waelen A, Veldhorst M, et al. Acute effects of breakfasts containing alpha-lactalbumin, or gelatin with or without added tryptophan, on hunger, "satiety" hormones and amino acid profiles. Br J Nutr. 2008;19:1-8.

60. Nishi T, Hara H, Tomita F. Soybean beta-conglycinin peptone suppresses food intake and gastric emptying by increasing plasma cholecystokinin levels in rats. J Nutr. 2003;133(2):352-357.

61. Aziz A, Anderson GH, Giacca A, et al. Hyperglycemia after protein ingestion concurrent with injection of a GLP-1 receptor agonist in rats:a possible role for dietary peptides. Am J Physiol Regul Integr Comp Physiol. 2005;289(3):R688-R694.

62. Bowen J, Noakes M, Clifton P. Role of protein and carbohydrate sources on acute appetite responses in lean and overweight men. Nutrition \& Dietetics. 2008;65(3):S71-S78.

63. Uneyama H, Niijima A, San Gabriel A, et al. Luminal amino acid sensing in the rat gastric mucosa. Am J Physiol Gastrointest Liver Physiol. 2006;291(6):G1163-G1170.

64. Jahan-Mihan A, Rodriguez J, Christie C, et al. The Role of Maternal Dietary Proteins in Development of Metabolic Syndrome in Offspring. Nutrients. 2015;7(11):9185-9217.

65. Dougkas A Östman E. Protein-Enriched Liquid Preloads Varying in Macronutrient Content Modulate Appetite and Appetite-Regulating Hormones in Healthy Adults. J Nutr. 2016;146(3):637-645.

66. Chungchunlam SM, Henare SJ, Ganesh S, et al. Effect of whey protein and a free amino acid mixture simulating whey protein on measures of satiety in normal-weight women. $\mathrm{Br} J$ Nutr. 2016;116(9):1666-1673.
67. Alireza Jahan-mihan, Corinne Labyak, Andrea Arikawa. The Effect of Characteristics of Proteins Fed during Gestation and Lactation on Development of Metabolic Syndrome in Dams and Male Offspring of Wistar Rats. Obes Sci Pract. 2017;3(2):224-232.

68. Soenen S, Westerterp-Plantenga M. Proteins and satiety: implications for weight management. Curr Opin Clin Nutr Metab Care. 2008;11(6):747-751.

69. Deibert P, König D, Schmidt-Trucksaess A, et al. Weight loss without losing muscle mass in pre-obese and obese subjects induced by a highsoy-protein diet. Int J Obes (Lond). 2004;28(10):1349-1352.

70. Wycherley TP, Moran LJ, Clifton PM, et al. Effects of energy-restricted high-protein, low-fat compared with standard-protein, low-fat diets:a meta-analysis of randomized controlled trials. Am J Clin Nutr 2012;96(6):1281-1298

71. Baer DJ, Stote KS, Paul DR, et al. Whey protein but not soy protein supplementation alters body weight and composition in free-living overweight and obese adults. J Nutr. 2011;141(8):1489-1494.

72. Belobrajdic DP, McIntosh GH, Owens JA. A high-whey-protein diet reduces body weight gain and alters insulin sensitivity relative to red meat in wistar rats. $J$ Nutr. 2004;134(6):1454-1458.

73. Kim J, Lee HJ, Kim JY, et al. Plant Proteins Differently Affect Body Fat Reduction in High-fat Fed Rats. Prev Nutr Food Sci. 2012;17(3):223-227.

74. Bong HY, Kim JY, Jeong HI, et al. Effects of corn gluten hydrolyzates, branched chain amino acids, and leucine on body weight reduction in obese rats induced by a high fat diet. Nutr Res Pract. 2010;4(2):106-113.

75. Melanson K, Gootman J, Myrdal A, et al. Weight loss and total lipid profile changes in overweight women consuming beef or chicken as the primary protein source. Nutrition. 2003;19(5):409-414.

76. Frestedt JL, Zenk JL, Kuskowski MA, et al. A whey-protein supplement increases fat loss and spares lean muscle in obese subjects:a randomized human clinical study. Nutr Metab (Lond). 2008;5:8.

77. Pal S, Ellis V, Dhaliwal S. Effects of whey protein isolate on body composition, lipids, insulin and glucose in overweight and obese individuals. Br J Nutr. 2010;104(5):716-723. 